\title{
The Policy Representation of Muslims in the US Media: A Case Study of the Newsweek Magazine (July to November 2001)
}

\section{Zahra Emamzadeh}

\author{
MA of American Studies, University of Tehran \\ Email: zemamzadeh@ut.ac.ir
}

\author{
Doi:10.5901/mjss.2014.v5n16p561
}

\begin{abstract}
The 9/11 attacks were a watershed in the history of the United States as it greatly influenced different aspects of the American society including its economy, politics, culture, and dominant ideology. It is no exaggeration to say that the 2001 terrorist attacks altered the American domestic and foreign policies. In this policy shift, the media played an important role since they were one of the main instruments which propagated and controlled the representation of different groups, especially Muslims, who came to be held accountable by the American mind for 9/11 attacks. The present thesis applies Saeid Reza Ameli's theory with regard to the representation of Muslims by westerners, classified into four major categories: Islamophilia, Islamoromia, Islamoverita, and Islamophobia. The present study aims to discuss the Islamophobic representational strategy as employed by the American weekly magazine of Newsweek two months before and two months after the 9/11 attacks. The research project uses Stuart Hall's representation theory to analyze Newsweek's articles about Islam before and after the 9/11 attacks. It also employs content analysis, and particularly SPSS, to come to a quantitative result about the dominant representational strategy of the magazine. After analyzing the findings, the researcher demonstrates the dominance of the Islamophobic representational strategy in the Newsweek magazine.
\end{abstract}

Keywords: 9/11 attacks, content analysis, Islamophobia, Newsweek, representation, SPSS, terrorism

\section{Introduction}

Many studies have been conducted to demonstrate the impact of one of the most detrimental incidents in the United State of America; i.e. the 9/11 attacks. The event had grave impacts on different aspects of the society: economy, politics, and even people's mindset. The September 11 attacks in 2001 are without a doubt one of the most significant determiners of the American domestic and foreign policy-making processes. The event had a wide range of effects. Many scholars have conducted research on different aspects of the issue. The present study, too, tries to shed light on one of the many aspects; i.e. Islamophobia.

The present study seeks to elaborate on Islamophobia as portrayed in the American media before and after the 9/11 attacks. To this end, the Newsweek magazine was chosen. In order to have a thorough grasp of the concept, the researcher decided to investigate the articles of the magazine from two months before and after the 9/11 attacks (JulyNovember 2001). It should be pointed out that the September issues, too, was examined. The articles were chosen from the "Worldview" and "War on Terror" sections of the magazine. There are different areas that the researcher tries to elaborate on in the present study. The results will be explained in the forth chapter.

The present study tries to shed light on one of the critical concerns of the 21th century, which has occupied the minds of many people especially Muslims. Islamophobia, which is as old as Islam itself, has re-emerged as an almost new phenomenon in this century. Islamophobia has a critical effect on the relationship between Muslims and nonMuslims. The effect of Islamophobia is not limited to the discourse between two people; it is a critical discourse between several civilizations and has a remarkable impact on the whole world. The present study tries to expound on Islamophobia and the other similar approaches to Islam, and then expatiate on a specific issue in the American media. The detailed information and what each chapter of the thesis contains are stated below.

\section{Statement of Problem}

Many scholars have investigated the influences that the 9/11 attacks had on different issues, e.g. the influences on the economy of the United State of America, the influences on their foreign policy, domestic influences, and so on. (Ameli, 2012. el-Aswad, 2013.Ghazali, 2007.Gottschalk \& Greenberg, 2008.) One the most important paths to deliver these 
effects is the media. The media is the key to spreading any ideas or policies. The present research seeks to provide an explanation of what happened after the 9/11 catastrophe and its effects on Islam. The present study aims at investigating the aspects of Islam that were depicted and those that were not depicted in the American media. Media has a broad scope; therefore, it is difficult to cover all of its areas. For this reason, the researcher decided to examine one of the weekly magazines that has a great deal of readers in the United State of America; the "Newsweek" magazine. Any weekly magazine consists of about 20 articles with different categorizations, e.g. economic, political, and social, among others. Two sections of the magazine were chosen for investigation, namely "World View" and "War on Terror".

The "War on Terror" section was added to the magazine after the 9/11 attacks. The very first issue that contained this section came out in October 2001. From October 2001 till the end of the period that was chosen to be analyzed in the present research, there are many articles sometimes more than 15 under this category, which makes it important to consider. The two categories "World View" and "War on Terror" will be described and analyzed in the Field Study section. The issue undertaken in the present study is investigating any policy shift in the attitude of the Americans toward Islam and Muslims.

Based on what has been explained above, the main question of the research is:

- Were the 9/11 attacks a policy shift in spreading Islamophobia in the United States of America; the case study of the Newsweek magazine?

The research also aims to discuss some relevant issue in this regard. It seeks to elaborate on the differences between the Islam represented in the Newsweek before and after the 9/11 attacks. Which Islam was presented in the Newsweek and which Islam was not presented in the Newsweek is also of importance.

By answering these questions, we can provide a clear image of the policy shift in Islamophobia after the 9/11 events.

\section{Theoretical Framework and Methodology}

In the present study, the researcher applied the representation theory of Stuart Hall (1997). Since the research tires to report whether the Islam presented in the West is an Islamophobic version, there should be a clear definition of Islamophobia. For this purpose, Ameli's (2012) classification of Islam and the West confrontation will be used. Ameli (2012) introduced four categories for this confrontation: 1) Islamophilia, 3) Islamoromia, and 3) Islamoverita (Islamotruth) and 4) Islamophobia. In the Theory section of the present study, the researcher will elaborate on these four categories.

Hall (1997) connects culture and meaning; it is our culture and our thought that we understand, and each person gets an explicit concept from a word, music, an image, etc. Our culture, identity, beliefs, rules, and norms affect our analysis and the sense of the aforementioned concepts. Therefore, meaning is not a fixed entity; it is flexible.

Hall (1997) defines representation as:

Using language to say something meaningful about or to represent the world meaningfully, to other people. Representation is an essential part of the process by which meaning is produced and exchanged between members of a culture. It does use of language, of sings and images which stand for or represent things. But this is far from a simple or straightforward process. (p. 15)

The method that is used in the present study is content analysis which is a quantitative method particularly SPSS software. The researcher tries to answer the main question by using content analysis in which the first step is choosing sample. The researcher has chosen the "World View" and "War on Terror" sections of the Newsweek magazine to analyze. A clear-cut elaboration and explanation about the methods and its application in material analysis is provided in the Methodology section. Content analysis refers to counting the times a word or a topic was used, a specific theme was elaborated, and also how much importance was given to each of them. Content analysis can be studied at three levels: 1) content analysis of the authors, 2) content analysis of the audience, and 3) content analysis of the message. The content analysis used in this research deals with the messages' (text) attitudes, values, and motivations (provided that the given material is a piece of writing). It is the meaning behind the expression of a word or a theme that matters (Payne \& Payne, 2004).

"Content analysis is used to analyze written and visual 'texts', including field notes. Counting versus interpreting. Example: conventions in newspaper 'coverage'. Designing content analysis research. Alternative models of the media: audience influence; political bias; commercial operations; electronic media" (Payne \& Payne, 2004, p. 51).

\section{Discussion and Conclusion}

The 9/11 attacks were a turning point in the history of the United States as the event greatly influenced different aspects 
of the American society including its economy, politics, culture, and dominant ideology. The 2001 terrorist attacks changed the American domestic and foreign policies. As was stated before, in this policy shift the media played a significant role since they were one of the main instruments which propagated and controlled the representation of different groups; especially Muslims who came to be held accountable by the American minds for the 9/11 attacks. The research project uses Stuart Hall's (1997) representation theory to analyze Newsweek's articles about Islam before and after the 9/11 attacks. Hall (1997) believes that meaning is not fixed and there are different interpretations about text (in Hall's opinion, text can be a film, article, etc.). The present study has applied Saeid Reza Ameli's (2012) theory with regard to the representation of Muslims by westerners. His theory is classified into four major categories: Islamophilia, Islamoromia, Islamoverita and Islamophobia. Islamophobia, the main key word for present project, means hatred toward Islamic issues and particularly Muslims all around the world. Islamoromia is a Western study of Islam, looking at Islam through Western eyes. Islamoverita is looking at Islam and Islamic issues neutrally, reflecting all the realities about Islam. Islamophilia offers an optimistic explanation of Islam and Islamic issues.

The main question of the research, as stated before, was:

- Were the 9/11 attacks a policy shift in spreading Islamophobia in the United States of America; the case study of the Newsweek magazine?

The hypothesis of the research was that the 9/11 attacks caused the policy shift regarding to Islamophobia and Islamophobic approaches in the Newsweek magazine. The present study has elaborated and discussed the Islamophobic representational strategy as employed by the American weekly magazine of Newsweek, two months before and two months after the 9/11 attacks.

It also employs content analysis, particularly SPSS, to come to a quantitative result about the dominant representational strategy of the magazine. After analyzing the findings, the researcher concludes that the statement about the dominance of the Islamophobic representational strategy in the Newsweek magazine is of significance.

Two sections of the Newsweek magazine were studied in this project (including "World View" and "War on Terror" sections). There are 32 articles discussed in this chapter, 16 of which belong to the "World View" section and the other 16 belong to the "War on Terror" section.

An important point that must be considered here is that the label neutral applies to those articles in which no reference to the four defined categories was made. After focusing and studying the entire defined project, the results and findings are explained.

First of all, brief lists of documented results are given. Afterwards, the relevant facts and findings are discussed.

There are 32 articles discussed in this study, 16 of which belong to the "World View" section and the other 16 belong to the "War on Terror" section. Among these32 articles, ten of them (31.3\%) were published before the 9/11 attacks and twenty-two of them (68.8\%) were published after 9/11.

Regarding the variable defined as "subject of text", it was found out that most of the articles are political and that they comprise 34.4 percent of the articles. Articles with a general subject, 25 percent, hold the second rank. It is significant to add that cultural and economic articles have the same percentage as the articles with a general subject, i.e., 25 percent. Historical articles, the last item, include only 3.1 percent of the articles.

With regard to the variable defined as "subcategory of a text's central subject", two categories of "post 9/11 threat" and "Islamic world" with the frequency of 18.8 percent hold the highest rank. After these two, the categories "violence" with 12.5 percent; "development" and "domestic policy" with 9.4 percent;" "jihad", "law issues", "religious issues", and "American dream" with 6.3 percent follow the above-mentioned subcategories. The "media" and "mixed" categories with only 3.1 percent are in the last place.

Most of the published materials in the journal, considering the variable of "region" in the text, are dedicated to America, with a frequency of 40.6 percent. The Middle East is in the second place with 28.1 percent. Among all the region categories, 15.6 percent is dedicated to universal materials, 9.4 to the west, and 6.3 to Asia.

In social trend of the text, modern materials are at the top with 40.6 percent. Postmodern materials and moderntraditional ones have the same rank; they both have 28.1 percent. Traditional materials cover3.1 percent of the articles.

The Pearson correlation coefficient value for the relation between variable of "date of publication" and the variable of "subject of the text" is 0.367 , and the Spearman correlation coefficient value for the relation between these two variables is 0.356 . Hence there is a meaningful correlation between these variables.

The Pearson correlation coefficient value for two variables; "date of publication" and "subcategory of text" is 0.359 and the "Spearman correlation coefficient" value for these two variables is 0.276 . Thus, there is a meaningful correlation between "date of publication" and "subcategory of text". Categories of "violence" and "Islamic world" mostly belong to post9/11 attacks. Three of these categories, namely "post 9/11 threat", "jihad", and "religious" are all published after 9/11. It is significant that two subcategories "jihad" and "religious" belong totally to the time after September 11 attacks. The 
categories defined as "domestic policy", "development", and "American dream" are mostly addressed in the texts before the attacks.

The Pearson correlation coefficient value for the two variables; "subject of the text" and "subcategory of the text" is 0.311 , and the Spearman correlation coefficient value for these two variables is 0.292 . There is a meaningful correlation between these two variables. The categories of "violence", "Islamic world", "post 9/11 threat", "domestic policy", and "American dream" are usually found in political texts. Among these all, of course the category of "domestic policy" is mostly found in political texts.

The Pearson correlation coefficient value for "discourse" and "region" is 0.209 , and the Spearman correlation coefficient value for these two is 0.229 . Therefore, there is a meaningful relation between discourse and region. The most Islamophobic discourse is related to the Middle East, which shows a correlation between Islamophobic discourses. The correlation coefficient value proves the existence of correlation between variables.

Regarding the "discourse of the text", as expected, the highest level belongs to Islamophobia, with 43.8 percent. After that, the neutral articles are in the second place with 37.5 percent. Islamoromia and Islamoverita are in the next place with 9.4 percent each. The figure below shows that a large number of studied articles, i.e., more than one third of the articles with the theme of Islam, are provided in the form of neutral texts. It is of significance that Islamophilia is not addressed in any articles studied. The chart below shows the result clearly.

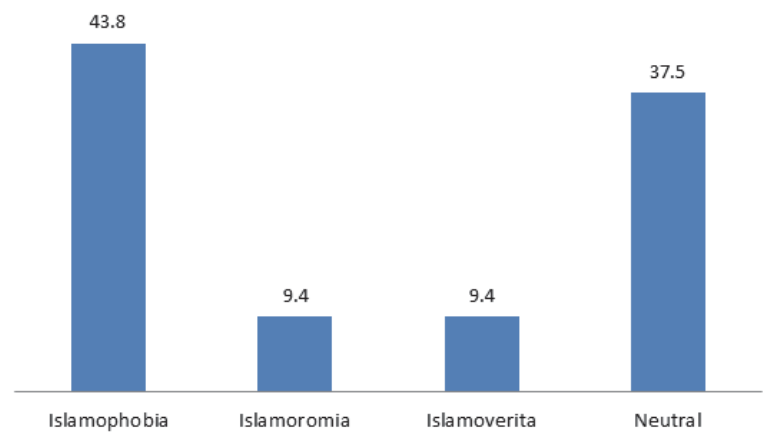

Islamophobia, as the most addressed discourse, is of great importance to be discussed and elaborated. Islamophobia, as defined in previous chapters, looks at Islam as a monolithic, inflexible, and static bloc. It also looks at Islam as a barbaric, irrational, primitive, sexist, and inferior religion in the west. Islamophobia considers Islam as an aggressive, threatening, and supportive of terrorism sect. In this kind of approach, Islam is considered also as an ideology, mainly used for political or military purposes. At another glance to the concept of Islamophobia, it can be mentioned that it views Islam as a faith, intolerant of Western criticism. Islamophobia can also be defined as anti-Islam hostility as a means to justify discrimination practices towards Muslims and exclusion of Muslims from the mainstream society, and anti-Islam hostility as a natural or normal phenomenon. (Ameli, 2012)

Islamoromia and Islamoverita are addressed both equally, 9.4 percent. Islamoromia consists of two parts, namely Islam and romia. Islamoromia is neither neutral nor for or against Islam. Islamoromia tries to represent Islam in the Roman (i.e., Western) context. Islamovertia tries to study Islam and Muslims as distinguishable entities; it tries to understand Islam and Muslims by considering their politics, economy, culture, and society, with regard to their historical background. The Islamoveritic approach is the product of a profound understanding and great effort to look at Muslims and Islam in a respectable and proper manner (Ameli, 2012). Referring to definitions of these two terms, it is clear that the texts that have either Islamoveritan or Islamoromian approaches cannot be considered as impartial materials as each are trying to address one aspect of Islam and do not consider all the dimensions of this religion. Therefore, the texts with either of these two approaches are not considered as fair descriptions of Islam and Muslim world.

The main hypothesis of this project is that the $9 / 11$ attacks caused a policy shift in spreading the Islamophobia concepts. As the statistics provided by this research shows, the Newsweek magazine treats Islam in an Islamophobic approach. As it was stated in the tables and figures above, 43.8 percent of the all the studied articles are Islamophobic. The below chart, provided by SPSS software shows this policy shift toward Islamophobia after the 9/11 attacks, which is the hypothesis of the present study. 


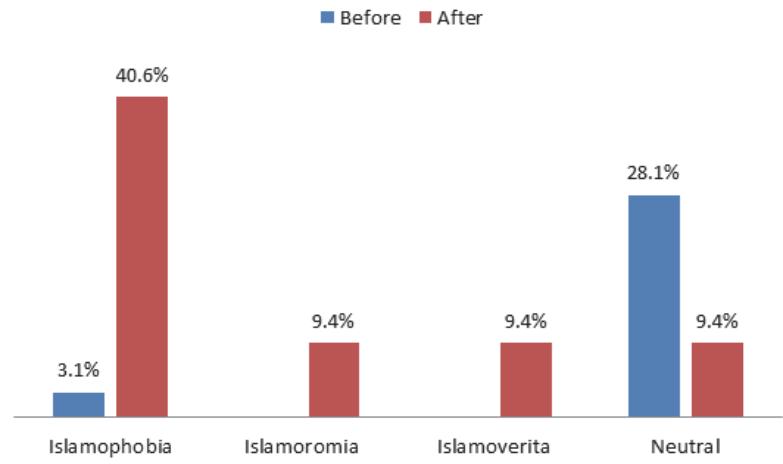

To clarify the articles that were labeled Islamophobic, the researcher provides a list name of some of Islamophobic articles, below.

- The article titled as "A Dictator's Dilemma" in "War on Terror" section, post 9/11 attacks.

- The article titled as "Meet the Bin Ladens" in "War on Terror" section, post 9/11 attacks.

- The article titled as "Go Well Beyond Well Prepared" in "War on Terror" section, post 9/11 attacks

- The article titled as "Confronting the Mob" in "War on Terror" section, post 9/11 attacks

Why these articles are found Islamophobic are discussed in field study section, and all the texts are provided in the appendix.

The chart below provides a comprehensive result about the frequencies of subcategories before and after the 9/11 attacks.

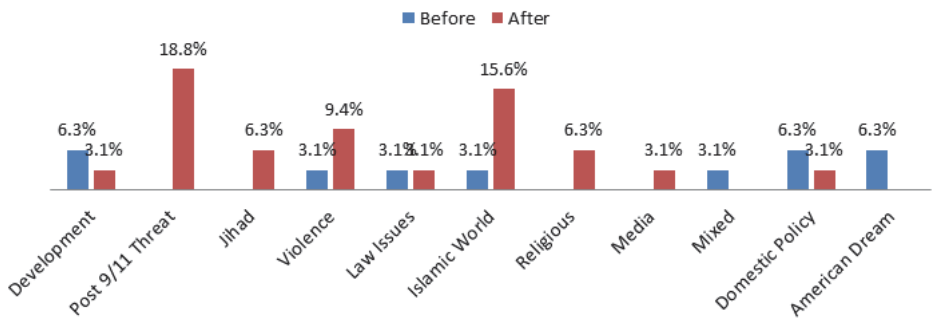

The subcategories such as "post 9/11 threat", "Islamic world", "jihad", "violence", and "religion" are mostly discussed after the $9 / 11$ attacks, which can be considered as a result of the increase in the distribution of Islamophobic approaches.

At the end, the research shows the policy shift caused by the 9/11 attacks in Islamophobic approaches in the Newsweek magazine.

\section{References}

Abdo, N. (2007). Eurocentrism, Orientalism, and Essentialism: Some Reflections on September 11th and Beyond. In Hawthorne, S. \& Winter, Bronwyn (Ed.), September 11, 2001: Feminist Perspectives. Melbourne: Spinifex Press Pty Ltd.

Ameli, S. R. (2012). Bibliogrlysisaphical Discourse Ana (Vol. 1). Wembley: Islamic Human Rights Commission.

Barker, C., \& GalasinÂski, D. (2001). Cultural Studies and Discourse Analysis. London: SAGE.

Barry, J., Moreau, R., \& Hussain, Z. (2001). Priority: Pakistan's Nukes. Newsweek, 138(20), 26.

Bartholet, J., Klaidman, D., Gutman, R., Nordland, R., Hosenball, M., Theil, S., \& ... Bociurkiw, M. (2001). Method To the Madness. Newsweek, 138(17), 54.

Bartholet, J., Norland, R., MacKinnon, I., Power, C., Lorch, D., \& Matthews, O. (2001).Inside the Mullah's Mind.Newsweek, 138(14), 30

Begley, S. (2001). Go Well Beyond 'Well Prepared.' (Cover story).Newsweek, 138(19), 33

Begley, S. (2001). Play Ball, But Ban The Backpacks. (Cover story).Newsweek, 138(19), 30.

Begley, S., Rogers, A., Isikoff, M., Klaidman, D., Rosenberg, D., Check, E., \& ... Downey, S. (2001). Unmasking Bioterror.(Cover story).Newsweek, 138(15), 20. 
Berger. (1991). Media research techniques. Newbury Park, CA: Sage.

Corner, J., Schlesinger, P., \& Silverstone, R. (Eds.). (2005). INTERNATIONAL MEDIA RESEARCH. London: Routledge.

Dawson, C. (2002). Practical Research Methods. United Kingdom: Oxford.

Derrida, J. (1976). Of Grammatology. (G. C. Spivak, Trans.) Baltimore: Johns Hopkins University.

Dickey, C., McGinn, D., Tyre, P., Pepper, T., \&Hosenball, M. (2001). Meet the bin Ladens. Newsweek, 138(16), 55.

Dyer, R. (1993). The Matter of Images: Essays on Representations. London and New York: Routledge.

El-Aswad, e.-S. (2013, Number 1). Images of Muslims in Western Scholarship and Madia after 9/11. Digest of Middle East Studies, pp. 39-56.

El Sawy, N. (2001). Yes, I Follow Islam, But I'm Not a Terrorist. Newsweek, 138(16), 12.

Ephron, D., Dickey, C., \& Zarembo, A. (2001).Confronting the Mob. Newsweek, 138(17), 50.

Fairclough, N. (1989). Language and power. London: Longman.

Foucault, M. (1980). Power Knowledge. Brighton : Harvester.

Ghazali, A. (2007). Islam \& Muslims in the Post-9/11 America.

Gottschalk, P., \& Greenberg, G. (2008). Islamophobia; Making Muslims the Enemy. plymouth: Rowman \& Littlefield.

Grossberg, L., Wartella, E., \& Whitney, D. C. (1998). MediaMaking: Mass Media in a Popular Culture. London: Sage.

Guterl, F. (2001).The Nagging Fear of Nukes. Newsweek, 138(15), 28.

Hall, S. (1980). Sociological Theories; Race and Colonialism. Paris: United Nations Educational Scientific and Cultural.

Hall, S. (1996). Critical Dialogues in Cultural Studies. (D. Morley, \& K.-H. Chen, Eds.) London: Routledge.

Hall, S. (1997). Representation: Cultural Representation and Singnifying Practices. (S. Hall, Ed.) London: Sage, in association with The Open University.

Hall, S., \& Gieben, B. (Eds.). (1995). Formation of Modernity. London: Open University.

Kent, R. (2001). Data Construction and Data Analysis for Survey Research. London: Palgrave Publication.

Liu, M., \& Moreau, R. (2001).Inside 'People Smuggling.'. Newsweek, 138(19), 52.

Longman Dictionary of Contemporary English. (2009). Iondon: Longman.

Macnamara, J. (2005). Media content analysis: Its uses; benefits and best practice methodology. Asia Pacific Public Relations Journal, 1-34.

Matthews, O. (2001). It's Like 'War of the Worlds.'. Newsweek, 138(17), 48.

McRobbie, A. (1991). Feminism and Youth Culture: From 'Jackie' to 'Just Seventeen'. Houndmills and London: Macmillan.

Neuendorf, K. (2002). The Content Analysis Guidebook. London: Sage.

Nordland, R., \& Hussain, Z. (2001).A Dictator's Dilemma. Newsweek, 138(14), 33.

Oxford Advanced Learner's Dictionary. (2001). Oxford: Oxford University Press.

Payne, G., \& Payne, J. (2004). Key Concepts in Social Research. London: Sage.

Thomas, E., Dickey, C., Liu, M., Hosenball, M., Ephron, D., Hammer, J., \& ... Zarembo, A. (2001). Handbook For the New War. Newsweek, 138(15), 34.

Weber, R. P. (1990). Basic Content Analysis. London: Sage.

Zakaria, F. (2001). America's New Balancing Act. Newsweek, 138(6), 37.

Zakaria, F. (2001). Be Productive--Hit The Beach. Newsweek, 138(8), 29.

Zakaria, F. (2001). Can Anybody Here Play This Game?.Newsweek, 138(4), 41.

Zakaria, F. (2001). Dick Gephardt, Unilateralist. Newsweek, 138(11), 37.

Zakaria, F. (2001). Israel's Best Plan: Build More Walls. Newsweek, 138(7), 33.

Zakaria, F. (2001).Keeping The War Alive. Newsweek, 138(9), 33.

Zakaria, F. (2001). Next: 'Nation-Building Lite.'. Newsweek, 138(17), 53.

Zakaria, F. (2001).Some Real Street Smarts. Newsweek, 138(5), 25.

Zakaria, F. (2001). The Allies Who Made Our Foes. Newsweek, 138(14), 34.

Zakaria, F. (2001). The End Of The End Of History. Newsweek, 138(13), 70.

Zakaria, F. (2001). The Myth Of The Super-Ceo. Newsweek, 138(10), 33.

Zakaria, F. (2001). The Politics Of Winning Wars. Newsweek, 138(21), 41.

Zakaria, F. (2001). There's More To Right Than Might. Newsweek, 138(2), 43

Zakaria, F. (2001).Time To Make Room For Daddy. Newsweek, 138(1), 39.

Zakaria, F. (2001). Time To Save 'Just In Time.'. Newsweek, 138(20), 38.

America Doesn't Need Crusades. (2001). Newsweek, 138(3), 33.

Bin Laden's Invisible Network. (2001). Newsweek, 138(18), 42.

Why Do They Hate Us? The Politics Of Rage.(Cover story).(2001). Newsweek, 138(16), 22. 